\section{A Integração Possível Entre o Processo de Descentralização e a Autonomia dos Serviços de Saúde e a Participação do Cidadão-Relato de Experiência}

Virginia Gawryszewski *

Este trabalho analisa a experiência de reorganização dos serviços de saúde da Região Emilia-Romana, na Itália, no seu perlodo mais recente, com ênfase nos aspectos da descentralização dos serviços, autonomia local e participação do cidadão. Conclui-se que a descentralização só foi possivel devido às caracteristicas da autonomia local e da participação do cidadão no processo, e que estes dois últimos fatores devem ser levados em conta no processo de reorganização de serviços atualmente em curso no Brasil.

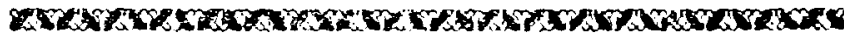

\section{INTRODUÇĀO}

O debate em tomo do processo de implementação da Reforma Sanitária brasileira tem sido feito dando ênfase aos seus determinantes e condicionantes políticos e econômicos. Nossa intenção com este trabalho é a de contribuir para a discussão das possíveis formas de reorganização dos serviços quando da implantação do Sistema Único de Saúde. Assim, faremos o relato da experiência de implantação do Sistema Nacional de Saúde italiano a nível regional, isto é, na Emilia-Romana ${ }^{* *}$, onde os princípios da Reforma Sanitária italiana foram implementados.

Analisaresmos os aspectos da descentralização dos serviços, com ênfase na autonomia local e na tão discutida participação da comunidade *** no processo de implementaçấo do novo sistema. Queremos mostrar com essa descrição, ainda que de forma preliminar, que a proposta de descentralização dos serviços de saúde só é possível se for garantida a autonomia do nível local e a participação do cidadão. O nosso fio condutor será o processo de programação, cujos pressupostos metodológicos são os do planejamento estratégico-situacional, já definidos por Rivera (11), e que resumimos a seguir:

Cadernos de Saade Pública, RJ, 7(1):17-25. jan/mar, 1991.
* Pesquisadora-assistente do De" partamento de Planejamento em Saude da Escola Nacional de Salude Pública - Fiocruz.

** Trabalho realizado com apoio financeiro do CNPq.

Usaremos neste texto o ter mo cidadão ao invés de comunidade, entendendowo como membro ativo de uma sociedade polf tica (9). 
- a programação se define como um ESPAÇO do planejamento determinado pela menor agregação do seu objeto (geográfico e de informação), pela sua loca lizaçâo institucional na periferia e pela maior abrangência temporal de sua proposta;

- ela deve ser entendida como um MOMENTO do planejamento, no sentido de que ocorre simultaneamente com ele e que se processa ciclicamente em um movimento de produção e construção;

- ela deve ter uma DIRECIONALIDADE, ... (que) nâo lhe é imposta desde for a por algum nivel superior, ... (e que) é o marco de referência essencial na definição dos problemas...;

- ela deve transbordar os LIMITES DOS FENÔME. NOS e penetrar na REDE DE CAUSALIDADE mais profunda para melhor definir e explicar os problemas; - (a programação local e regional) deve participar do MESMO MOVIMENTO operacional (de comparação e sintese) para assegurar o cumprimento da diretriz de integração institucional e programática;

- (a programação local) deve comportar um movimento de DESCENTRALIZAÇÃO do aparelho institucional, que garanta a participação efetiva da população no planejamento;

-'os sistemas de planejamento e de programação devem estar regidos pelas premissas ... (de) INSEPARA. BILIDADE entre planejamento, programação e gerência, REDEFINIÇÁO constante de metas e trajetórias, $C R I A C ̧ A ̃ O$ de um sistema de avaliação e de monitores estratégicos permanentes, busca ativa da VIABILIDA$D E$, através da análise dos atores e seus projetos (Os grifos são nossos).

\section{IMPLEMENTANDO OS PRINCÍPIOS DA REFORMA SANITÁRIA}

A Regiāo Emilia-Romana está situada ao Norte da Itália, apresentando uma vasta planície, o que possibilitou o desenvolvimento da agricultura e da pecuária. Foi lá que nasceram as primeiras associaçōes de trabalhadores anarquistas e socialistas, que tinham como objetivo uma reforma radical do quadro institucional e a instauração de um regime político que garantisse maior liberdade e democracia para todos. Ao longo da história italiana, estes objetivos tomaram-se largamente conhecidos, passando a ser denominados de "modelo reformista emiliano". Durante os anos do fascismo, foi a região italiana que mais contribuiu na luta pela resistência $(3,10)$. Com a criação oficial das Regiōes italianas, a partir de 1970, a Regiāo Emilia-Romana pode dar curso legalmente às suas propostas de autonomia local. Esta Região adotou, ao longo de sua história político-institucional, a programaçã̃o 
das ações como elemento viabilizador das propostas políticas dos grupos hegemônicos no poder. Em 1983, o Conselho Regional (equivalente à nossa Assembléia Legislativa) aprovou as normas de reordenamento institucional, o que implicou dar maior impulso à idéia de conjugar autonomia à programação, colocando as organizações de nivel local em condições de serem atores primários no governo e nas intervenções programadas, com o objetivo de transformação (6). Programar* para eles significa uma ação dos poderes públicos para satisfazer às necessidades e interesses coletivos e para a orientação da atividade econômica (pública e privada), para a realização de interesses gerais e grandes exigências nacionais** (4). Consideram viável tal proposição mesmo em regimes capitalistas, pela possibilidade de pré-determinar as linhas da ação econômica, apesar do Estado italiano não utilizar a programação, mesmo que fosse usada somente no sentido da sua própria racionalização***

A política de programação na Região Emilia-Romana foi implementada com muita dificuldade entre dois períodos particularmente significativos para a política italiana. O primeiro período ocorreu na década de 60 , cujos determinantes foram o desenvolvimento das forças produtivas e uma grande confiança numa política de reformas, que, porém, não teve o alcance desejado devido ao conflito permanente entre o discurso reformista e a prática conservadora das forças no poder. O segundo período foi na década de 70 , durante o governo de solidariedade nacional, cujo momento era o de uma grave crise econômica com diminuição da capacidade de desenvolvimento das forças produtivas, que também não avançou devido à falta de compromisso político do bloco de forças no poder, de tendência conservadora, na implementaçâo de políticas reformistas (4).

As conseqüências dessa situação particular do Estado italiano não foi das melhores para a Região Emilia-Romana, já que a não-implementação de uma política de programação a nível central comprometeu a possibilidade de transformá-la num elemento confiável a nível local. A falta de uma política de reformas do Estado, em geral, e na administração pública, em particular, atrasaram o desenvolvimento da política de programação regional, e que só pôde realizar-se plenamente após a implantação do Sistema Nacional de Saúde, em 1979, embora, durante a década de 70 , tenham sido realizadas experiências vitoriosas em algumas Regiōes.

Concordamos com Grassi (4), quando ele diz que enfrentar o tema da programação significa rediscutir os conteúdos da própria concepção de desenvolvimento, redefinir a relação entre a economia e a política,
- O termo programação é entendido por nós como sinónimo de planejamento, ja que em seus documentos raramente aparece o termo planejamento.

** Esta e outras citaçōes mencionadas no decorrer do texto foram traduzidas do original para facilitar a sua compreensão.

*** O termo racionalizaçāo é aqui entendido como integrante do enfoque tradicional do planejamento económico. 
colocar-se o problema de como pode ser realizado um governo com base no crescimento econômico, em que direção e de que forma selecionar os objetivos, as prioridades, as compatibilidades. Com isso, seriam dois os principais atributos da programação: a globalidade e a territorialidade.

A globalidade da programação deve consistir, acima de tudo, numa abordagem complexa da realidade econômica e social e na individualização dos objetivos estratégicos do desenvolvimento, o qual ... permanece sempre como o parâmetro e o objetivo da politica de programação, sob pena desta limitar-se a uma simples modalidade de administrar e não de gerenciar.

Neste sentido a programação assume uma fisionomia policêntrica, isto é, envolve a pluralidade dos centros de decisão públicos (as instituiçōes democráticas) e privados (por exemplo, as empresas) não somente como exigência democrática para a definição dos interesses gerais, mas também como reconhecimento da competência autônoma da programação, $e$ da possibilidade dos diversos sujeitos de elaborar $e$ adotar programas para alcançar objetivos coerentes com as linhas gerais já dadas.

A territorialidade, por seu lado, vem a ser definida através da sua dimensẫo, isto é, a dimensão territorial ótima para a programaçấo é, por excelência, a regional.

Apesar das grandes dificuldades para o desenvolvimento da política de programação a nível do Estado italiano, a Região Emilia-Romana, ao adotar este método e seus instrumentos, respaldou-se nas profundas raízes culturais que enfatizaram o papel central das Comunas (menor divisão administrativa do Estado italiano) como principal representante local, e na tradição de participação democrática do operariado urbano e rural.

Como já foi dito anteriormente, a possibilidade que a Regiāo Emilia-Romana teve de desenvolver plenamente sua política de programação no setor saúde ocorreu a partir da promulgação da Lei do Sistema Nacional de Saúde de 1979. Neste novo contexto, a programação passou a ter duas atribuições. A primeira, ser método de governo do novo sistema de saúde. A segunda, ser instrumento para a transformação do sistema pré-existente, no sentido indicado pela Lei.

Todo o arcabouço metodológico que foi desenvolvido perpassou três pilares: autonomia local, descentralização e participação do cidadão. Do ponto de vista da programação propriamente dita, foram quatro as diretrizes fundamentais para a realização do I Plano Regional de Saúde (1980-1983), isto é: a) desenvolver a gestão coordenada dos serviços de saúde; b) promover e desenvolver intervençōes específicas na área de

Cadernos de Saúde Pública, RJ, 7(1):17-25, jan/mar, 1991. 
prevenção; c) reorganizar e qualificar a rede hospitalar e d) realizar iniciativas no campo da formação profissional (4).

As primeiras avaliações realizadas apontaram para resultados positivos, apesar do caráter experimental do Plano e da falta de bases técnicas mais sólidas e da formação profissional deficiente de administradores e operadores dos serviços.

Do ponto de vista do processo de programação, alguns pontos críticos insolúveis, tanto técnicos quanto políticos, limitaram uma melhor performance do Plano. O primeiro deles foi a inexistência de um sistema de informação organizado a nível nacional, que pudesse consolidar dados estatísticos e epidemiológicos, com o objetivo de uma maior aproximação do diagnóstico de situação e posterior desenvolvimento das atividades. $O$ segundo deles foi o financiamento realizado através do Fundo Nacional de Saúde, que não condizia com as necessidades apontadas no Plano, já que o percentual dos recursos que foram repassados às regiōes para serem aplicados nos projetos o foram, na realidade, sem levar em consideração o estabelecido no artigo 51 da Lei: ... na base de indicadores definidos pelos gastos corrente e de capital (1).

Do ponto de vista da estruturação dos serviços, a Região Emilia-Romana foi uma das primeiras a implantar as Unidades Locais de Saúde (estrutura operativa do Sistema Nacional de Saúde)* , e desenvolver ações observando os princípios básicos da Lei que definiu o novo sistema, iniciando, assim, a reversão do quadro de disfunção instịtucional caracterizado pela maior ênfase dada às atividades de nível hospitalar e curativas do que às atividades preventivas e de nível ambulatorial.

A elaboração do II Plano Regional de Saúde (aprovado em 1989) parte, dessa forma, de um patamar organizativo dos serviços, em que passa a ser possível desenvolver novas técnicas e aprofundar outras, através de estudos experimentais. Mas não é só isso, analisar e fazer a revisão dos procedimentos organizativos não é somente um exercício técnico, que altera o percurso dos documentos ou das informaçôes, que induz transformaçōes nas responsabilidades dos profissionais de saúde, na carga de trabalho, na agilização decisória, mas torna-se também o instrumento que altera as formas de poder dos grupos no interior das organizaçóes e modifica algumas regras do jogo, ocultas ou nẩo (5). A partir do entendimento desses aspectos, aliado à compreensão da necessidade da integração dos novos projetos, a elaboração do II Plano Regional de Saúde passa a ser realizada com base no binômio eficiência operacional da organização e melhor qualidade do serviço para o usuário.
* Para maiores detalhes, ver aro tigo de Giovanni Berlinguer: - As tarefas das Unidades Locais de Saúde". In: Salude em Debate $n: 25$, junho de $1989, p .69-79$. 
Assim, a consolidação do sistema regional de saúde vem se dando reforçando seus aspectos organizativos, como também desenvolvendo atividades que digam respeito ao perfil epidemiológico da população e suas exigências de qualidade, o que pode ser confirmado na seguinte frase: $O$ final de um percurso que represente uma mudança cultural em relação aos problemas da eficácia e eficiência organizativa e um comportamento orientado para essa mudança poderão ser concretizados pela constituição de unidades de intervenção organizativa que catalizem as necessárias agregaçöes de energias e compromissos na solução dos problemas, sempre novos, que sempre se manifestaram na vida das Unidades Locais de Saúde, assim como em qualquer tipo de organização (2).

As formas organizativas que são propostas continuam a aprofundar-se no sentido da mudança da estrutura institucional como principal cenário de uma mudança possivel, isto é, através da potencialização dos serviços de prevenção e dos serviços para a atenção extra-hospitalar (12).

Os instrumentos que vêm sendo desenvolvidos são múltiplos, de natureza e fontes variadas, caracterizando o acompanhamento do avanço científico-tecnológico que vem ocorrendo no mundo de hoje.

O elemento central para o desenvolvimento dos instrumentos de programação, organização e gestão dos serviços é aquele relativo à qualidade dos serviços. A partir da percepção de que a dinâmica ambiental é permanente, isto é, está em movimento constante, e da necessidade de antecipar o futuro, isto é, tornar o sistema govemável, as atividades desenvolvidas nas Unidades Locais de Saúde têm se caracterizado por valorizar a autonomia decisória destas organizaçōes, além de uma maior integração entre elas. Assim, estão sendo criadas as condiçōes para uma gestão que dê respostas às várias incertezas que predominam no sister a de saúde, dentre elas a do financiamento, considerada por muitos a de maior poder de determinação na implementação do próprio sistema (7).

Nessa direção, os projetos desenvolvidos na Região Emilia-Romana têm como pano de fundo a introdução de uma proposta de mudança gerencial no interior das Unidades Locais de Saúde, e são os seguintes: a implantação de um sistema de custos, de um sistema de informação, da programação-orçamentária descentralizada até o nível dos serviços locais, o acompanhamento das atividades hospitalares através do método DRG (Diagnosis Related Groups) e a avaliação da relação custos/benefícios em todas as ações realizadas. 


\section{DISCUTINDO A INTEGRAÇÃO POSSÍVEL}

A descrição acima foi realizada tomando-se por base uma das dimensōes da questão da descentralização, que são os aspectos organizacionais do sistema. Embora não esteja explicitada de que forma ocorre a participação do cidadâo, ela expressa-se tanto dentro quanto fora dos aspectos descritos.

O Estado italiano tem um nível de organização que permite o acesso, seja da sociedade civil organizada (partidos políticos, associações de moradores, associaçōes de doadores de sangue etc), seja do simples cidadẫo, na participação direta das decisões (através dos instrumentos do referendum e do abaixo-assinado, entre outros). A sociedade italiana vem passando por um periodo de transição, em função da complexificação das relações sociais, que faz com que estejam sendo percorridos novos caminhos nas formas de participação do cidadão. O projeto de reforma da autonomia local, que até agora não foi aprovado pelo Parlamento italiano e que garantiria maior poder de decisão às Comunas, expressa a riqueza de propostas que têm surgido ao longo destes anos na Itália. Um dos debates gira em torno da necessidade de se avançar na discussão do conceito de DEVER (tanto por parte do Estado quanto por parte do cidadão) introduzindo o conceito de $P O$. $D E R$ (aqui com maior ênfase para o cidadão) e criando instrumentos para efetivamente exercer este poder, isto é, que a participaçâo não seja mais definida em termos de assembleismo ou de simples participação ou controle sobre as decisóes administrativas, mas seja cada vez mais próxima de uma demanda de eficácia, não de eficiência, mas de eficácia dos serviços públicos, dos serviços sociais e dos serviços de interesse coletivo no território (8).

Alguns instrumentos sāo apresentados, como, por exemplo, o de superar o caráter "voluntarista" das Associaçōes de Moradores, reconhecendo-as como órgãos da Comuna, extendendo para elas a delegação de competência, através de novas formas de regulamentaçẫo.

A riqueza destas propostas tem também expressão no âmbito da saúde. Todo o processo de discussão do Plano Regional de Saúde tem sido realizado considerando-se nẩo somente as instâncias formais políticoadministrativas do Estado, que, no caso, são as Assembléias Legislativas Regionais, cujos representantes sāo eleitos, mas também a participação da sociedade civil organizada (partidos políticos e associaçōes civis) na definição dos principais pressupostos para a ação no Sistema Regional de Saúde. No momento do acompanhamento e controle do Plano, da avaliação do impacto das açōes desenvolvidas pelos serviços na saúde da 
população, quer sob o aspecto técnico ou político, a discussão é feita principalmente com as associações civis voltadas para a questão da qualidade da atenção aos individuos, que, inclusive, podem solicitar, a qualquer momento, a discussão de algum tema relevante para a melhoria da qualidade dos serviços.

\section{CONCLUSŌES}

Todo o movimento que vem sendo realizado na direção da descentralizaçấo dos serviços passa, hoje, na Emilia-Romana, por uma fase de amadurecimento, caracterizada principalmente pela presença de um conjunto de serviços de saúde que tem assegurado uma resposta satisfatória para a grande maioria da demanda, pelo enraizamento destes serviços no território e pela preservação da política anteriormente definida, apesar dos efeitos da não-aprovação do Plano Nacional de Saúde, desde a implantaçẩo do Sistema Nacional de Saúde. A complexidade desse momento pode ser assim expressa: num mundo onde a velocidade das mudanças sociais é cada vez mais acelerada, a simples manutençâo de uma situação, embora relativamente eficiente, só pode conduzir na direção de uma perspectiva de declínio do serviço, risco que deve ser afastado através de uma incisiva política de desenvolvimento $e$ transformação (12).

A tese de que a descentralização dos serviços é possível, se for garantida a autonomia do nível local e a participação do cidadão, é confirmada, ainda que numa primeira aproximação, através desse relato de experiência, entendendo a questão nas suas devidas proporçōes, isto é, considerando o contexto político, econômico e cultural da sociedade em foco. A riqueza da experiência que vem sendo implementada na Região Emilia-Romana vem servindo de exemplo para a reorganização dos serviços de saúde no Estado italiano, possibilitando, também, a difusão de novas idéias e concepções acerca do processo de planejamento e organizaçấo de serviços de saúde para outros países capitalistas, inclusive para o nosso.

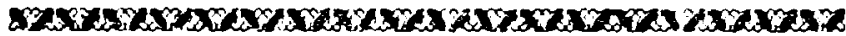

This paper analyses the experience of health service reorganization in an italian region, Emilia-Romagna, enphasysing the aspects of service decentralization, local autonomy and citizen participation. It is concluded that the autonomy and the citizen 
participation were fundamental for the decentralization process. Is suggested that the study of that experience can contribute to the health reorganization process now in course in Brazil.

\section{REFERÊNCIAS BIBLIOGRÁFICAS}

1. BERLINGUER, G. - Una Riforma per la Salute. Bari, De Donato, 1979. Anexo 1, 279p.

2. DEME, E. - "L'Evoluzione delle teorie organizzative e la progettazione organizzativa nell'Unita Sanitaria Locale". In: L'Azienda Sanitd̀, Miläo, Franco Angeli, 1988, p. 73-88.

3. GA WRYSZEWSKI, V. Reorganizaçăo dos Serviços de Sadide da Itália e algumas reflexōes sobre a experiência brasileira. Rio de Janeiro, Escola Nacional de Saúde Pablica, 1985. Dissertaçåo de Mestrado, $70 \mathrm{p}$.

4. GRASSI, A. e PELLACANI, F. - La Programazione Sanitaria da Modello Teorico a Prassi di Governo, Milåo, Franco Angeli, $1985,282 \mathrm{p}$.

5. GUIZZARDI, M - Progetto Sperimentale di Interventi Organizzativi nelle Unitd̀ Sanitarie Locali. Modena, Regione Emilia-Romagna, 1989.

6. L'UNITA - Il nuovo quadro di ruoli e funzione per Regione, Province e Comuni. 2/11/83. Itália.

7. MENEGUZZO, M. - "Dalla Planificazione formale alla programmazione strategica". In: L'Azienda Sanitd, Milăo, Franco Angeli, 1988, p. 281-286.

8. MORO, G. - "La sfida della democrazia diretta". In: Partecipazione e nuovi poteri dei cittadini, Democrazia e diritto (suppl.) 4-5, luglio-ago, 1989, p. 87-92.

9. QUINTANA, J. B. - "Cidadão". In: Dicionário de Ciências Sociais, RJ, FGV, 1986, 1421 p., p. 177-178.

10. REGIÄO EMILIA-ROMAGNA - Casa è la Regione EmiliaRomagna, Bolonha, Ed. Ufficio Stampa della Giunta Regionale dell'Emilia-Romagna, 1983, 50 p.

11. RIVERA, F. J. U. - "A programação Local de Saúde, Distritos Sanitários e Enfoque Estratégion". In: Planejamento e Programaçâo em Saúde - Um enfoque estratégico, (Rivera, F. J. U., org.), SP, Cortez, 1989, p. 177-202.

12. VÁRIOS - "Da qui al $2000^{\prime \prime}$ - Rev. Come, Bologna, n: 1, p. 1, fev. 1989. 